This is the final version (unedited) of the paper published in Journal of Planar Chromatography 25 (2012) 3, 220-224.

DOI: $10.1556 /$ JPC.25.2012.3.6

http://akademiai.com/content/e 78575m6112552n2/?p=81962db92f50439293dc6942b7e8035c $\& \mathrm{pi}=6$

\title{
Application of direct bioautography and SPME-GC-MS for the study of antibacterial chamomile ingredients
}

Ágnes M. Móricz*, Szabolcs Szarka, Péter G. Ott, Dóra Kertesy, Éva B. Héthelyi, Éva Szőke, Ernő Tyihák

Á.M. Móricz, P.G. Ott, and E. Tyihák, Plant Protection Institute, Centre for Agricultural Research, Hungarian Academy of Sciences, Herman O. Str. 15, H-1022 Budapest, Hungary; E-mail:moricz.agnes@agrar.mta.hu

Sz. Szarka, D. Kertesy, É.B. Héthelyi, and É. Szőke, Department of Pharmacognosy, Faculty of Pharmacy, Semmelweis University, Üllői Str. 26, H-1085 Budapest, Hungary

Corresponding author:

Ágnes M. Móricz, Plant Protection Institute, Centre for Agricultural Research, Hungarian Academy of Sciences, Herman O. Str. 15, H-1022 Budapest, Hungary; Tel.: 0036-48-77-515; Fax.: 0036-48-77-555; E-mail: moricz.agnes@agrar.mta.hu

Key Words: antibacterial activity, TLC/OPLC-direct bioautography, chamomile (Matricaria recutita L.), SPME-GC-MS, spiroethers, herniarin, (-)-alpha-bisabolol

\section{Summary}


The isolation and characterization of antibacterial chamomile components were performed by the use of direct bioautography and solid phase microextraction (SPME)-GC-MS. Four ingredients, active against Vibrio fischeri, were identified as the polyacetylene geometric isomers cis- and trans-spiroethers, the coumarin related herniarin, and the sesquiterpene alcohol (-)-alpha-bisabolol.

\section{Introduction}

Chamomile (Matricaria recutita L.), with its aromatic white flowers and grown as a field crop in many countries, is one of the most popular and widely known herbs in traditional as well as modern folk medicine in Hungary. Chamomile flower is employed as ingredients of herbal teas and as a component of many tinctures and extracts for the treatment of e.g. indigestion, inflammations, and cramps. The beneficial effects of chamomile, such as anti-inflammatory, sedative, analgesic, spasmolytic, antioxidant and antimicrobial properties [1-4], are related to different classes of therapeutically interesting ingredients, like essential oil components, flavonoids, and coumarin derivatives $[1,5,6]$.

The antimicrobial activity of volatile oils and crude extracts of chamomile has been widely studied. The chamomile oil, extracted by steam distillation, is composed mainly of sesquiterpenoids ((-)-alpha-bisabolol, bisabolol-oxides, and chamazulene (the artefact of matricine by distillation)) and polyines (cis- and trans-spiroethers) [7]. The essential oils showed antimicrobial activity against various species of bacteria, fungi and viruses [8-11], however, Gram-positive bacteria were found more susceptible than Gram-negative ones [9]. Generally the aqueous chamomile extracts were more effective against molds and yeast than bacteria, while the alcoholic ones showed higher activity against the growth of bacteria $[12$, 13]. The hydroalcoholic chamomile extracts contain also coumarins (herniarin, 
umbelliferone), which are phytoalexins [14], exhibiting a very weak antibacterial and a stronger antifungal activity $[15,16]$.

Direct bioautography (DB) [17-22] can be used to visualise the activity of different matrix components separated by planar layer chromatography against cells in the adsorbent bed. Therefore, it is suitable for guiding the isolation of effective compounds e.g. from plant extracts. Our earlier DB results showed that alcoholic chamomile extracts contain ingredients with antibacterial activity against Pseudomonas savastanoi pv. phaseolicola [23], luminescence gene tagged Pseudomonas syringae pv. maculicola and Bacillus subtilis [19]. In our most recent studies the isolation and identification of some components of $50 \%$ aqueous ethanol chamomile flower extract, working antibacterially against $P$. maculicola and B. subtilis, have been achieved using overpressured layer chromatography (OPLC) [24-27] with on-line detection and fraction collection and subsequent GC-MS analyses [22]. In the most active fractions cis-, trans-spiroethers, and the coumarins herniarin and umbelliferone were identified.

Solid phase microextraction (SPME) is a recently developed technique, which was introduced in the early 1990s. The target analytes can be adsorbed on the SPME fiber by immersing it in the sample or by exposing it to the sample headspace, in which case the matrix interferences can be drastically reduced [28-30]. The main advantages of this technique are simplicity of operation, speed, its solventless nature, analyte selectivity and preconcentration, and the possibility of the easy coupling to a powerful analytical tool, the gas chromatography-mass spectrometry [31].

In this paper the characterisation of antibiotic chamomile ingredients is presented using TLC/OPLC-DB with luminescent Vibrio fischeri bacteria and SPME-GC-MS.

\section{Experimental}




\section{Materials}

Aluminum foil-backed normal particle silica gel $60 \mathrm{~F}_{254}$ plates (TLC, \#5554 from Merck, Darmstadt, Germany) were used for TLC separation, as well as for OPLC but in this case the layers were sealed at all four edges (OPLC-NIT, Budapest, Hungary). All used solvents were of analytical grade from Reanal (Budapest, Hungary). Test substances (-)-alpha-bisabolol, and herniarin were from Sigma-Aldrich (Budapest, Hungary).

\section{Preparation of extracts}

Chamomile (Matricaria recutita L.) flowers were obtained from Hungarian drug store chains (JuvaPharma and Herbaria) as well as collected in the end of May 2011, in Harta (in the Great Plain, Hungary); the latter sample is dried at $25{ }^{\circ} \mathrm{C}$, in the dark. $1500 \mathrm{mg}$ of flowers were extracted with $10 \mathrm{~mL}$ of $50 \%$ ethanol in a $20 \mathrm{~mL}$ screw-capped glass bottle by maceration and shaking (Dragon Lab SK-L330-Pro digital linear shaker) for three-times $2 \mathrm{~h}$ within $24 \mathrm{~h}$. After filtration (filter paper MN 616 from Reanal) with the help of vacuum the solutions were stored at $5{ }^{\circ} \mathrm{C}$ and applied for TLC/OPLC-DB and isolation.

\section{TLC and OPLC separations}

TLC separation of the components of $50 \%$ aqueous ethanol chamomile extract was performed with chloroform-acetone $99: 1(\mathrm{v} / \mathrm{v})$ as a mobile phase in an unsaturated chamber on preconditioned $\left(130{ }^{\circ} \mathrm{C}, 3 \mathrm{~h}\right)$ normal particle size silica gel layers with $10 \mathrm{~cm}$ height. The samples were applied at $12 \mathrm{~mm}$ height with Linomat IV sample applicator (CAMAG, Muttenz, Switzerland) or a microsyringe. In 2D-TLC the sample was applied in a spot, $12 \mathrm{~mm}$ far from the edges. The first dimension was developed as described above and afterwards the dried plate was chromatographed in the $2^{\text {nd }}$ dimension with chloroform-acetone 95:5 (v/v). 
Personal OPLC BS50 system (OPLC-NIT, Budapest, Hungary) [24-26] was used for infusion OPLC [27]. The infusion operating mode means that we don't let the mobile phase flow out of the layer, therefore, the separated components remain on it, which can be achieved by closing of the mobile phase outlet. Conditions of the separation were as follows: $20 \mathrm{~cm} \times 20$ $\mathrm{cm}$ sealed TLC chromatoplate, sample application in bands at $3 \mathrm{~cm}$ from the edge, $50 \mathrm{bar}$ external pressure, $400 \mu \mathrm{L}$ rapid mobile-phase flush, $400 \mu \mathrm{L} \min ^{-1}$ mobile phase flow rate, $4414 \mu \mathrm{L}$ mobile phase, $672 \mathrm{~s}$ development time. The mobile-phase was pure chloroform.

The chromatoplates, developed by TLC or infusion OPLC, were dried by cold air stream using a hair-dryer (5 min). The chromatographic spots were visualised using a UV lamp ( $\lambda=$ $365 \mathrm{~nm}$ ) (CAMAG), vanillin-sulphuric acid reagent $(40 \mathrm{mg}$ vanillin $+10 \mathrm{~mL}$ ethanol +200 $\mu \mathrm{L}$ concentrated sulphuric acid; the dipped plate was heated to $110{ }^{\circ} \mathrm{C}$ for $5 \mathrm{~min}$ ), a Shimadzu CS-930 dual-wavelength TLC scanner (Shimadzu Co., Kyoto, Japan) at $350 \mathrm{~nm}$, and in direct bioautographic systems.

For isolation of active ingredients, $0.5 \mathrm{~mL}$ extract was applied in a $17 \mathrm{~cm}$ wide band. After development, the appropriate chromatographic bands marked under UV light were scraped off and extracted with acetone. The antibacterial activity of the concentrated (by cold air stream) extracts was checked with TLC-DB. The identification was performed with SPME-GC-MS analyses of the extracts and/or by the comparison of $R_{f}$ value of active components with test substances.

\section{Bioassay}

The antibacterial effect of separated chamomile components was evaluated in vitro with direct bioautography (DB) [17-22] against the Gram-negative, naturally luminescent, marine bacterium Vibrio fischeri. The $V$. fischeri strain (Lumistox test strain, Hach-Lange Ltd.) was grown at $28.3{ }^{\circ} \mathrm{C}$ in the dark with good aeration until it reached an optical density of $2.3-2.6$, 
i.e. for ca. 4-5 h, in the following liquid medium (slightly modified recipe of NCAIM, Corvinus University, Budapest; ingredients are expressed in $\mathrm{g} \mathrm{dm}^{-3}$ ): pepton 5, yeast extract 5, meat extract 6, $\mathrm{NaCl} 24, \mathrm{MgSO}_{4} 3.4, \mathrm{MgCl}_{2} * 6 \mathrm{H}_{2} \mathrm{O}$ 5.3, $\mathrm{KCl} 0.7, \mathrm{CaCl}_{2}$ 0.1.

For detection of the bioluminescent light emission, the dried, developed chromatoplates were immersed into a cell suspension of Vibrio fischeri (for $5 \mathrm{~s}$ ), put into a transparent glass cage ensuring an air phase above the adsorbent layer and protecting against drying. The bioautograms were documented immediately after inoculation by use of a computercontrolled cooled CCD camera (IS-4000, Alpha Innotech, San Leandro, USA) with an exposure time of 2-4 min. The light emitted by the bacterial cells is closely dependent on reductive metabolic activity (which in turn depends on viability), so the darker areas on the images indicate lack of metabolic activity.

\section{Solid phase microextraction (SPME)}

The air-dried and powdered chamomile inflorescence was put into $20 \mathrm{~mL}$ headspace vials sealed with a silicone/Polytetrafluoroethylene (PTFE) septum. Acetone extracts of appropriate chromatographic bands were carefully evaporated to dryness at room temperature in similar vials prior to SPME-GC-MS analyses. The static headspace solid phase microextraction sample preparation was carried out with a CTC Combi PAL (CTC Analytics AG, Zwingen, Switzerland) automatic multipurpose sampler using a $65 \mu \mathrm{M}$ StableFlex polydimethylsiloxane/divinylbenzene (PDMS/DVB) SPME fiber (Supelco, Bellefonte, PA, USA). After an incubation period of $5 \mathrm{~min}$ at $100{ }^{\circ} \mathrm{C}$, the extractions were performed by exposing the fiber for $20 \mathrm{~min}$ at $100{ }^{\circ} \mathrm{C}$ to the headspace of a $20 \mathrm{~mL}$ vial containing the plant material. Then the fiber was transferred immediately to the heated injector port of the GCMS, and desorbed for $1 \mathrm{~min}$ at $250^{\circ} \mathrm{C}$. The SPME fiber was cleaned and conditioned in the Fiber Bake-out Station in pure nitrogen atmosphere at $250{ }^{\circ} \mathrm{C}$ for $15 \mathrm{~min}$ after desorption. 


\section{Apparatus and GC-MS Conditions}

The analyses were carried out with an Agilent 6890N/5973N GC-MSD (Santa Clara, CA, USA) system equipped with an Agilent HP-5MS capillary column (30 m $\times$ $250 \mu \mathrm{m} \times 0.25 \mu \mathrm{m})$. The $\mathrm{GC}$ oven temperature was programmed from $60^{\circ} \mathrm{C}(3 \mathrm{~min}$ isothermal) to $200{ }^{\circ} \mathrm{C}$ at $8{ }^{\circ} \mathrm{C} / \mathrm{min}\left(2 \mathrm{~min}\right.$ isothermal), $200-230{ }^{\circ} \mathrm{C}$ at $10^{\circ} \mathrm{C} / \mathrm{min}(5 \mathrm{~min}$ isothermal) and finally $230-250{ }^{\circ} \mathrm{C}$ at $10{ }^{\circ} \mathrm{C} / \mathrm{min}(1 \mathrm{~min}$ isothermal). High purity helium was used as carrier gas at $1.0 \mathrm{~mL} / \mathrm{min}(37 \mathrm{~cm} / \mathrm{s})$ in constant flow mode. Injector temperature was $250{ }^{\circ} \mathrm{C}$ and the split ratio was $1: 20$.

The mass selective detector was equipped with a quadrupole mass analyzer and was operated in electron ionization mode at $70 \mathrm{eV}$ in full scan mode (40-500 amu at $3.2 \mathrm{scan} / \mathrm{s})$. Data were evaluated by MSD ChemStation D.02.00.275 software (Agilent). The identification of the compounds was carried out by comparing retention times and recorded spectra with data of authentic standards. Mass spectral and retention data known from the literature [7, 32-34] and the NIST 05 library were also consulted.

\section{Results and discussion}

The antibacterial components of $50 \%$ aqueous ethanol extracts of chamomile from different sources were screened by the high-throughput, fast, and cheap TLC-DB using Vibrio fischeri as a test microorganism. According to the result (Figure 1), all samples were rich in compounds having an inhibiting/killing effect against these bacteria (see black areas). The bands of the active ingredients, which were visible under UV light ( 3 components at $R_{f} 0.65$, 0.5 , and 0.34 ), were scraped off and extracted with acetone. The TLC-DB evaluation of all 3 extracts confirmed their antibiotic effect against $V$. fischeri (Figure 2). However, it seemed 
that the active ingredients 1 and 2 could transform to each other. These transformations could have had occurred on the adsorbent layer, so they were also observed by a 2D-TLC (Figure 3). Therefore, it was thought that those two components are geometric isomers, which suggestion was further examined by SPME-GC-MS analyses. The SPME-GC-MS total ion current (TIC) chromatogram of air-dried and powdered chamomile inflorescence demonstrates that the volatile part of chamomile flower is a complex mixture comprising principally sesquiterpenes ((-)-alpha-bisabolol, bisabolol-oxides $\mathrm{A}$ and $\mathrm{B}$, farnesene, spathulenol), acetylene-derivatives (spiroethers), and the coumarin-related herniarin (Figure 4a). In spots 1 and 2 (at $R_{\mathrm{f}} 0.65$ and 0.5 ) (Figure 1) both cis- and trans-spiroether isomers (Figure $4 b$ ) whereas in spot 3 (at $R_{f} 0.34$ ) herniarin were detected (not shown). According to the ratio of isomers, the cis isomer was determined as the component at $R_{f} 0.65$, while the other component with lower $\mathrm{R}_{\mathrm{f}}(0.5)$ was identified as trans-spiroether.

The antibacterial effect of (-)-alpha-bisabolol, one of the main volatile components of chamomile, was examined against $V$. fischeri using OPLC-DB. The forced flow OPLC provides faster, better separation, more compact chromatographic spots (more sensitive detection) than conventional TLC/HPTLC; therefore, the application of this technique can be very attractive for the separation of components of complex matrices. The presence of the not UV active (-)-alpha-bisabolol in the 50\% aqueous ethanol chamomile extract was recorded by making it visible with vanillin-sulphuric acid reagent (Figure 5a-5c) as well as by GC-MS measurements [22]. Figure 5 shows that besides cis- and trans-spiroethers as well as herniarin, also (-)-alpha-bisabolol inhibited/killed $V$. fischeri bacteria cells. Though, the extract did not contain (-)-alpha-bisabolol in appropriate concentration that could appear as inhibiting zone. The confirmation of the observable chromatographic spots obtained from various visualisation methods also can be seen in Figure 5. In fact, among the components of the 50\% 
aqueous ethanol extract the cis and trans spiroethers (these are also components of the chamomile essential oil) generate significant antibacterial activity to $V$. fischeri.

\section{Conclusions}

These results show that planar layer chromatography, especially forced flow OPLC coupled with DB is a very useful tool for guiding the detection and directed isolation of antibacterial compounds. This high throughput and relatively cheap technical solution enables simple as well as fast chemical and biological screening of complex matrices such as plant extracts, aiding the discovery of new, efficient antimicrobials for which there is a high demand because of the growing resistance of pathogens to the majority of presently known and used antibiotics $[35]$.

Although components of chamomile are mainly used for medical purposes, their use can be extended e.g. for food or cosmetic applications as well. The volatile components are chemically sensitive molecules; therefore, they in pure form need to be stored in airtight containers in the dark in order to prevent chemical changes.

\section{Acknowledgement}

This work was supported by OTKA grant No. PD83487.

\section{References}

1. N.G. Bisset and M. Wichtl, Herbal Drugs and Phytopharmaceuticals: A Handbook for Practice on a Scientific Basis, 2nd ed.; CRC Press: Boca Raton, FL, 2001. 
2. World Health Organization. Monographs on Selected Medicinal Plants, vol. 1: Flos Chamomillae. WHO, Geneva, 1999.

3. J.K. Srivastava, and S. Gupta, in R.R. Watson (ed.) Complementary and Alternative Therapies in the Aging Population, Elsevier Inc., Academic Press. 2009.

4. D.L. McKay, and J.B. Blumberg, Phytother. Res. 20 (2006) 519-530.

5. É. Szöke, E. Máday, S.A. Kiss, L. Sonnewend, and É. Lemberkovics, J. Am. Coll. Nutr. 23 (2004) 763S-767S.

6. M. Repcák, J. Imrich, and M. Franeková, J. Plant Physiol. 158 (2001) 1085-1087.

7. É. Szöke, E. Máday, E. Tyihák, I.N. Kuzovkina, and É. Lemberkovics, J. Chromatogr. B. 800 (2004) 231-238.

8. M. Lis-Balchin, S.G. Deans, and E. Eaglesham, Flavour Fragr. J. 13 (1998) 98-104.

9. M.E. Aggag, and R.T. Yousef, Planta Med. 22 (1972) 140-144.

10. M. Berry, Pharm. J. 254 (1995) 191-193.

11. K.M. Soliman, and R.I. Badeaa, Food Chem. Toxicol. 40 (2002) 1669-1675.

12. K.M. Al-Ismail, and A. Talal, Agric. Sci. 30 (2003) 330-337.

13. M. Cinco, E. Banfi, A. Tubaro, and R.D. Loggia, Int. J. Drug. Res. 21 (1983) 145-151.

14. M. Daniel, and R.P. Purkayastha, Handbook of Phytoalexin Metabolism and Action. Dekker Inc: New York, 1995.

15. T. Ojala, S. Remes, P. Haansuu, H. Vuorela, R. Hiltunen, K. Haahtela, and P. Vuorela, J. Ethnopharmacol. 73 (2000) 299-305.

16. U. Afek, J. Orenstein, S. Carmeli, V. Rodov, and J.M. Bar, Phytochemistry. 50 (1999) 1129-1132.

17. L. Botz, S. Nagy, and B. Kocsis, in Sz. Nyiredy (ed.) Planar Chromatography - A Retrospective View for the Third Millennium, Springer, Budapest, 2001.

18. C. Weins, and H. Jork, J. Chromatogr. A, 750 (1996) 403-407. 
19. Á.M. Móricz, E. Tyihák, and P.G. Ott, J. Planar Chromatogr. 23 (2010) 180-183.

20. Á.M. Móricz, Gy. Horváth, P. Molnár, B. Kocsis, A. Böszörményi, É. Lemberkovics, and P.G. Ott, J. Planar Chromatogr. 23 (2010) 406-410.

21. I.M. Choma, and E.M. Grzelak, J. Chromatogr. A 1218 (2011) 2684-2691.

22. Á.M. Móricz, Sz. Szarka, P.G. Ott, É.B. Héthelyi, É. Szőke, and E. Tyihák, Med. Chem. 8 (2012) 85-94.

23. E. Tyihák, E. Mincsovics, Gy. Kátay, Zs. Király-Véghely, A.M. Móricz, and P.G. Ott, J. Planar Chromatogr. 21 (2008) 15-20.

24. E. Mincsovics, M. Garami, L. Kecskés, B. Tapa, Z. Végh, Gy. Kátay, and E. Tyihák, 82 (1999) J AOAC Int. 587-598.

25. E. Tyihák, E. Mincsovics, and Á.M. Móricz, J. Chromatogr. A 1232 (2012) 3-18.

26. E. Mincsovics, and E. Tyihák, Nat. Prod. Commun. 6 (2011) 719-732.

27. E. Mincsovics, É. Sárdi, I. Velich, Gy. Kátay, and E. Tyihák J. Planar Chromatogr. 15 (2002) 280-285.

28. C.L. Arthur, and J. Pawliszyn, Anal. Chem. 62 (1990) 2145-2148.

29. H. Lord, and J. Pawliszyn, J. Chromatogr. A 885 (2000) 153-193.

30. M. Riu-Aumatell, M. Castellari, E. López-Tamames, S. Galassi, and S. Buxaderas, Food Chem. 87 (2004) 627-637.

31. P. Arias Abrodo, D. Díaz Llorente, S. Junco Corujedo, E. Dapena de la Fuente, M.D. Gutiérrez Álvarez, and D. Blanco Gomis, Food Chem. 121 (2010) 1312-1318.

32. R.P. Adams, Identification of essential oil components by gas chromatography/quadrupole mass spectroscopy. Allured Publ. Corp.: Carol Stream, USA, 2001. 
33. A. Iordache, M. Culea, C. Gherman, and O. Cozar, Nucl. Instrum. Methods Phys. Res. B 267 (2009) 338-342.

34. É. Szöke, E. Máday, J. Gershenzon, J.L. Allen, and É. Lemberkovics, J. Chromatogr. Sci. 42 (2004) 229-233.

35. J.N. Eloff, S. Afr. J. Sci. 96 (2000) 116- 118.

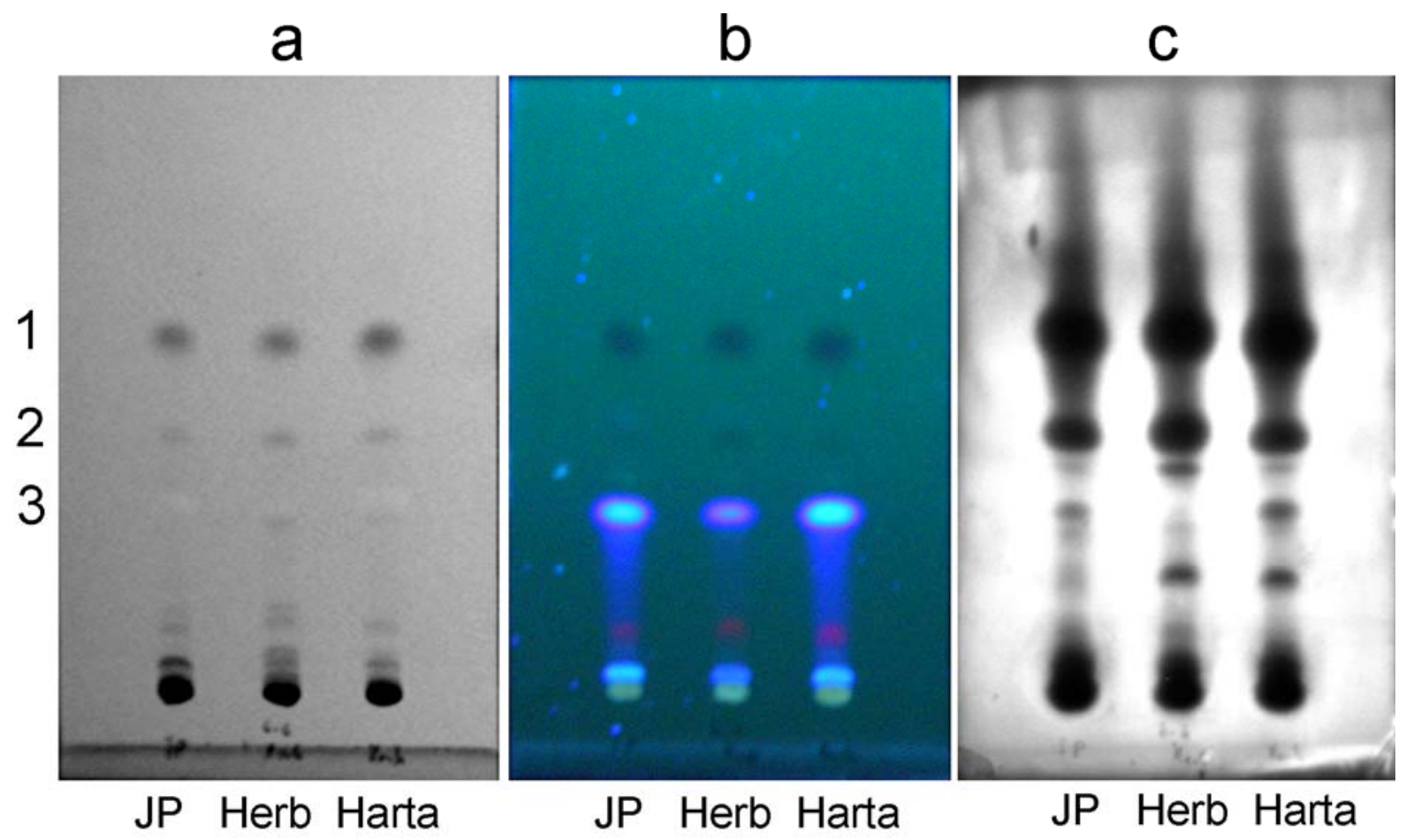

Figure 1

Detection of ingredients of $50 \%$ aqueous ethanol extracts ( $4 \mu \mathrm{L}$ of each) of chamomile obtained from JuvaPharma (JP) and Herbaria (Herb) as well as collected in Hungary in the Great Plain (Harta). The isolated antibacterial UV active components (1,2 and 3) were separated by TLC.

$\mathrm{a} / \mathrm{b}-$ the developed layers under UV light $\lambda=254 / 365 \mathrm{~nm}$

$\mathrm{c}-$ bioautogram using Vibrio fischeri (dark spot $=$ inhibition zone $)$ 


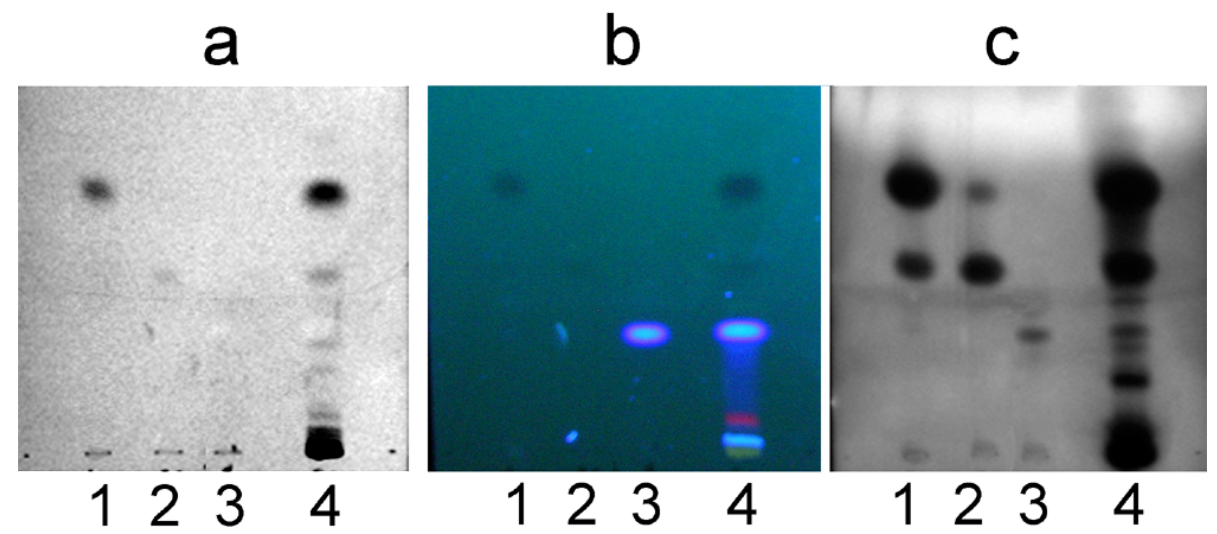

Figure 2

Detection of ingredients of whole chamomile extract and the isolated antibacterial UV active components separated by TLC; 1, 2, 3- isolated chamomile components extracted from the chromatographic bands at $R_{f} 0.65,0.5$, and 0.34 , respectively (see Figure 1), $4-6 \mu \mathrm{L}$ of $50 \%$ aqueous ethanol extract of chamomile collected in Harta $\mathrm{a} / \mathrm{b}-$ the developed layers under UV light $\lambda=254 / 365 \mathrm{~nm}$ $\mathrm{c}-$ bioautogram using Vibrio fischeri (dark spot $=$ inhibition zone) 


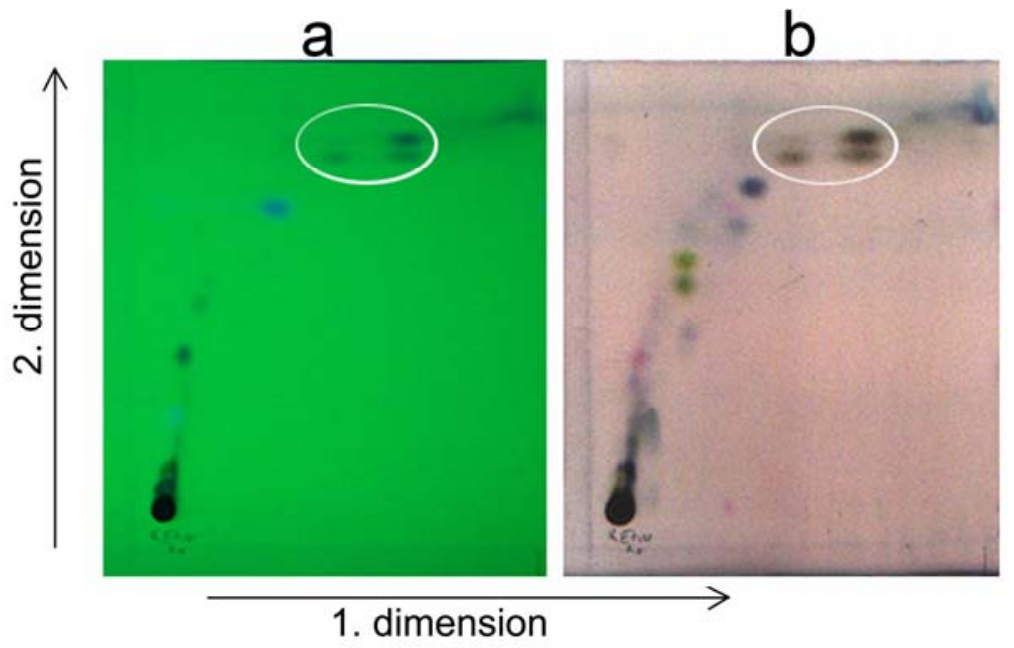

Figure 3

2D-TLC separation of $10 \mu \mathrm{L}$ of $50 \%$ aqueous ethanol extract of chamomile obtained from JuvaPharma. The circled area shows the spontaneous transformation of the 2 components to each other.

a - the developed layers under UV light $(254 \mathrm{~nm})$

$\mathrm{b}$ - visualisation with vanillin-sulphuric acid reagent 

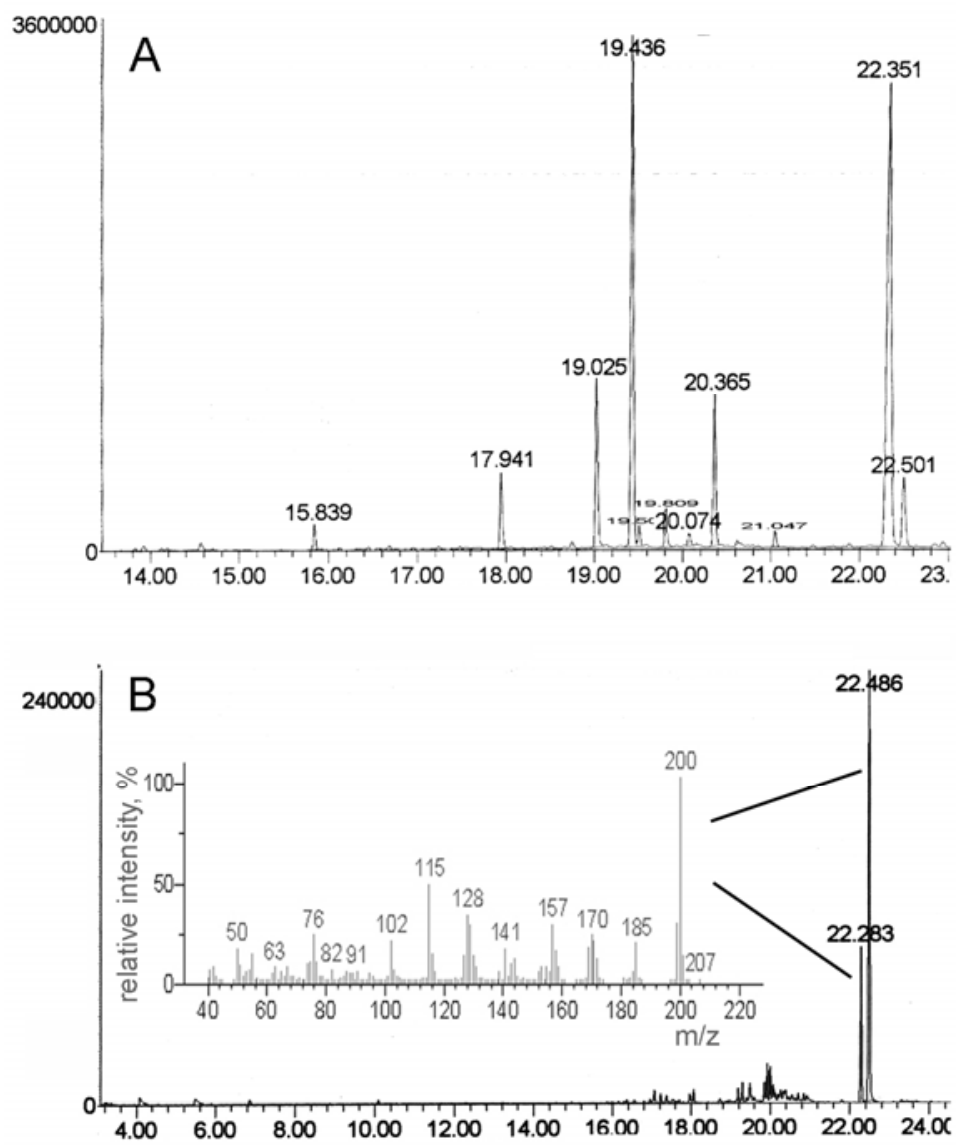

Figure 4

TIC chromatograms of (a) $5 \mathrm{~g}$ of dried powered chamomile flower (JuvaPharma) and (b) isolated chamomile components extracted from the chromatographic bands at $\mathrm{R}_{\mathrm{f}} 0.5$ with their mass spectra obtained by SPME-GC-MS analysis;

Peaks at different $t_{R}$ were identified as: $15.8 \mathrm{~min}$ - trans-beta-farnesene, $17.9 \mathrm{~min}$ spathulenol, $19.0 \mathrm{~min}$ - bisabolol-oxide $\mathrm{B}, 19.4 \mathrm{~min}$ - (-)-alpha-bisabolol, $20.0 \mathrm{~min}-$ herniarin, $20.3 \mathrm{~min}$ - bisabolol-oxide A, $22.3 \mathrm{~min}$ - cis-spiroether, $22.5 \mathrm{~min}$ - trans-spiroether 

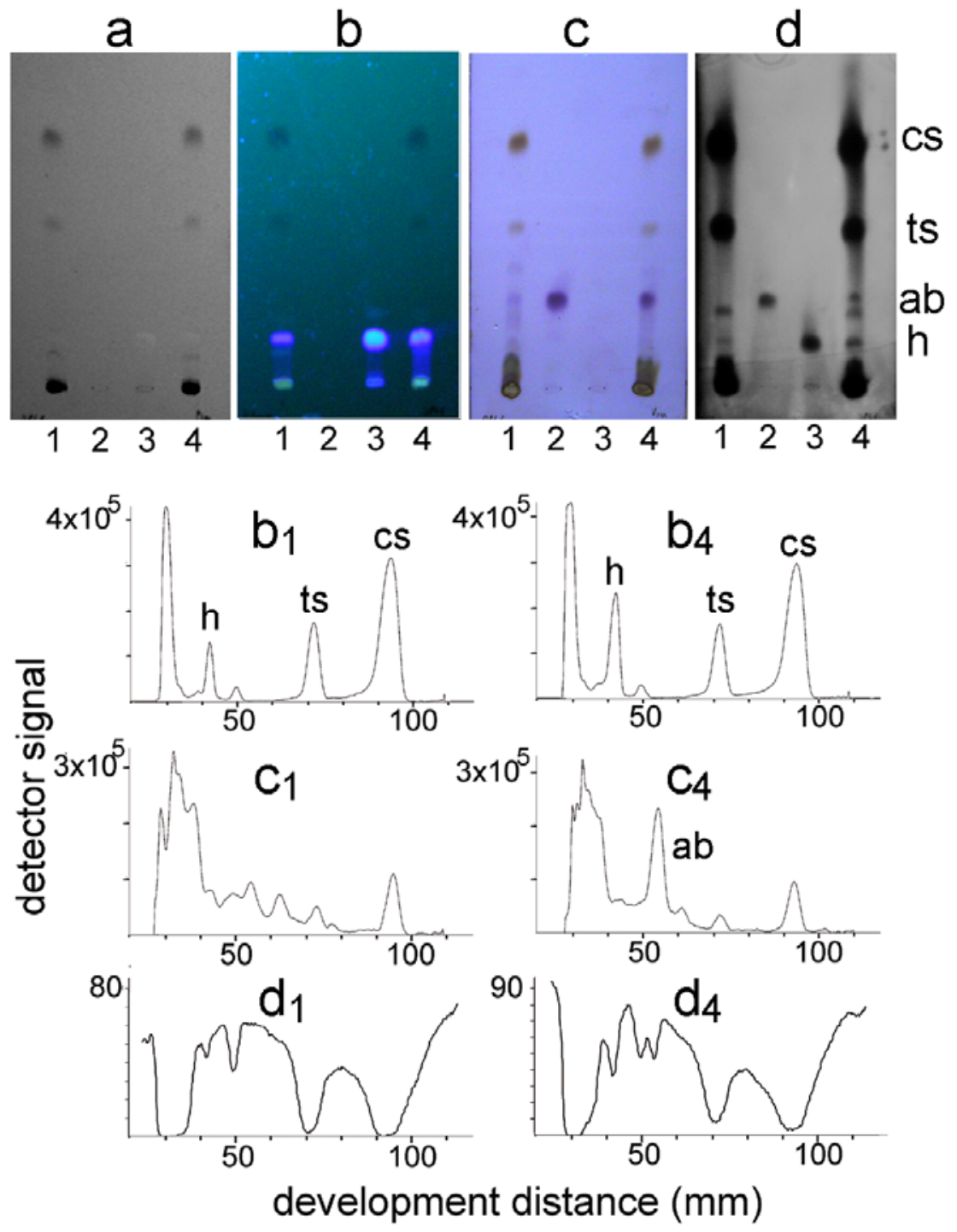

Figure 5

Detection of ingredients of $50 \%$ aqueous ethanol chamomile extract separated by infusion

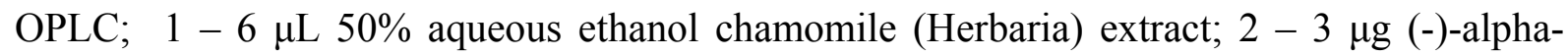
bisabolol; $3-3 \mu \mathrm{g}$ herniarin; $4-6 \mu \mathrm{L} 50 \%$ aqueous ethanol chamomile extract $+1.5 \mu \mathrm{g}$ of each (-)-alpha-bisabolol and herniarin test substances

$\mathrm{a} / \mathrm{b}-$ the developed layers under UV light $\lambda=254 / 365 \mathrm{~nm}$

$\mathrm{c}-$ visualisation with vanillin-sulphuric acid reagent

$\mathrm{d}$ - bioautogram using Vibrio fischeri (dark spot = inhibition zone)

$b_{1}$ and $b_{4}-$ densitometric evaluation of tracks 1 and 4 in Figure $5 b$ at $350 \mathrm{~nm}$ 
$\mathrm{c}_{1}$ and $\mathrm{c}_{4}-$ densitometric evaluation of tracks 1 and 4 in Figure $5 \mathrm{c}$ at $600 \mathrm{~nm}$

$\mathrm{d}_{1}$ and $\mathrm{d}_{4}-$ the measurement of the intensity of the luminescent light in tracks 1 and 4 in Figure $5 d$

cs - cis-spiroether, ts - trans-spiroether, ab - (-)-alpha-bisabolol, $\mathrm{h}$ - herniarin 